\title{
Sexual Health Perceptions Among First-Year Students at a British University
}

\section{Rusi Jaspal}

To cite this article: Rusi Jaspal (2019): Sexual Health Perceptions Among First-Year Students at a British University, American Journal of Sexuality Education

To link to this article: https://doi.org/10.1080/15546128.2019.1701597

册 Published online: 18 Dec 2019.

Submit your article to this journal $₫$

Q View related articles $\sqsubset$

View Crossmark data \lceil 


\title{
Sexual Health Perceptions Among First-Year Students at a British University
}

\author{
Rusi Jaspal \\ Faculty of Health and Life Sciences, De Montfort University, Leicester, United Kingdom
}

\begin{abstract}
First-year undergraduate students in the United Kingdom undergo significant change in their lives as they embark upon their university experience. They may be exposed to various social and psychological factors that increase their risk of poor sexual health. Indeed, epidemiological data suggest that young people (including students) face sexual health inequalities compared to the general population. People's perceptions are key to understanding their behavior. This study explores the sexual health perceptions of a group of first-year students at a British university. Sixteen heterosexual students were interviewed, and the data were analyzed using qualitative content analysis. The analysis revealed three content categories: (1) sexual freedom and exploration at university, (2) university environmental sexual risk factors, and (3) stigma as a barrier to sexual health. These risk factors can undermine sexual health outcomes in students in the long term and should, therefore, be considered in sexual health education programs for university students in the United Kingdom. It is argued that the incorporation of social and psychological factors into such programs will lead to more effective sexual health promotion in this high-risk population.
\end{abstract}

\section{KEYWORDS}

Sexual health; sexuality; identity; university students

\section{Introduction}

When starting university, young people go through new and important changes in their lives. For many, going to university coincides with their transition from adolescence to adulthood. Many move away from home and live away from their parents for the first time. During this transition period, students create new friendships and relationships, enter new social groups, and develop a sexual identity (Patton, Renn, Guido, \& Quaye, 2016). However, they may also be exposed to various social and psychological factors that increase their risk of poor sexual health. Indeed, epidemiological data suggest that university students and young people, more generally, face sexual health inequalities compared to the general

CONTACT Rusi Jaspal $@$ rusi.jaspal@cantab.net $\mathbf{E}$ Faculty of Health and Life Sciences, De Montfort University, Leicester, United Kingdom 
population (Chanakira, O'Cathain, Goyder, \& Freeman, 2014; Public Health England, 2019). Risk factors include inter alia inaccurate risk perception, peer group pressure, decreased psychological wellbeing and alcohol misuse. University students are a significant population partly because there has been a dramatic increase in the number of people choosing to go to university in the UK. Participation in higher education among young people reached $49 \%$ in 2015, indicating that almost half of all young people now decide to go to university (Department for Education, 2007). Moreover, universities are diverse contexts with students from a wide range of cultural backgrounds and geographical areas (Jaspal, 2015).

As a key population in sexual health epidemiology, university students should be a focus of empirical research in this area but there is a gap in knowledge concerning the sexual health perceptions of university students in the United Kingdom. Accordingly, this study explores the sexual health perceptions of a group of first-year undergraduate students at a British university, focusing on risk perception, social norms concerning sex, and their reported sexual behavior at university. A key aim of the study is to inform recommendations for an effective sexual health education program for university students.

\section{Sexual health among university students}

There is a high incidence of sexually transmitted infections (STI) among young people (aged 15-24) in the UK. In 2017, there were 420,000 STI diagnoses in England and 144,000 of them (34.2\%) were among people aged 15-24 (Public Health England, 2018a). In 2017, young people accounted for $63 \%$ of all chlamydia diagnoses and $37 \%$ of all gonorrhea diagnoses. Public Health England (2019) show that, between 2017 and 2018, there was a $24 \%$ increase in gonorrhea incidence (from 16,517 to 20,453) and an 11\% increase in syphilis diagnoses (from 950 to 1055). In $2018,1,304,113$ chlamydia tests were carried out on people aged 15-24 and 131,269 tests came back positive (representing a $10.1 \%$ positivity rate).

These data must be considered in view of the fact that many young people do not regularly screen for STIs, which means that many are living with undiagnosed infections and potentially transmitting them to others. Indeed, there was a reported $8 \%$ drop in chlamydia testing among people aged 15-24 between 2014 and 2015 (Public Health England, 2015). In 2017, 11.5\% of new HIV diagnoses (502 out of 4363) were among people aged 15-24 (Public Health England, 2018b). While there are no epidemiological data on university students, in particular, most students are within this high-risk age group (Department of Education, 2017) and, as discussed 
next, there are various factors that can increase the risk of poor sexual health in this population.

\section{Risk factors for poor sexual health}

There has been remarkably little research into sexual health among university students in the United Kingdom and most studies of young people include university students but tend not to focus on them (e.g. Lorimer, Reid, \& Hart, 2009). Chanakira et al. (2014) study of university students in Northern England is a notable exception. Vivancos, Abubakar, and Hunter (2008) note that university students are at risk of STIs given the potential for sexual risk behavior across a variety of university-based activities. Some of the risk factors for poor sexual health include inaccurate risk perception; social norms in relation to sexuality; decreased psychological wellbeing; negative attitudes toward condoms; and alcohol misuse.

\section{Inaccurate risk perception}

Inaccurate risk perception (that is, believing that one's risk is lower than it actually is) is associated with poor sexual health. Collado, Johnson, Loya, Johnson, and Yi (2017) have shown that students are less likely to use an available condom or to postpone sex until a condom becomes available if their sexual partner is seen as more desirable. The authors attribute this finding to the perception that a desirable partner is less likely to have an STI and thus, "low risk". Crucially, knowledge is associated with risk perception. In their interview study of college and university students in South East England, Goundry, Finlay, and Llewellyn (2013) found that knowledge of STIs was generally poor - especially in relation to the link between STIs and infertility. Their research suggests a need to increase STI and sexual health knowledge through effective awareness-raising interventions. It is also important to focus on students' own perceptions and definitions of "having sex", sexual risk and sexual health. Indeed, in one study, it was found that only one-third of students surveyed perceived oral-genital contact as "having sex", although perceptions varied in accordance with age and gender (Pitts \& Rahman, 2001). This is important because, although oral sex may not be perceived as having sex, objectively the practice does carry significant risks for sexual health.

\section{Social norms in relation to sexuality}

Social norms in relation to sexuality are key, as they encourage particular perceptions and patterns of behavior and discourage others. Young people are more likely to engage in sexual risk behaviors when such behaviors are 
"social permissible" within their peer networks (Gardner \& Steinberg, 2005). This may constitute a strategy to "fit in" and to derive a sense of belonging within their group. Furthermore, social values, such as sexual conservatism, impacts perceptions.

In a questionnaire study of 125 female and 93 male university students, Foster and Byers (2008) found that students who had higher levels of sexual conservatism and who did not personally know somebody who had had an STI had higher expectations of adverse judgement related to STI. Moreover, sexual conservatism and higher dissatisfaction with universitybased sexual health education were associated with STI-related shame. The authors conclude that social and sexual norms are central to understanding both STI-related stigma and shame.

Gender norms and attitudes are also important. Hayter and Harrison (2008) note that there are gendered attitudes toward sexual relationships among adolescents in England. More specifically, they claim that young men are socialized into behaviors that can increase the social pressure on young women to engage in sexual behavior - often under the influence of alcohol, which can, in turn, increase the risk of poor sexual health.

Norms and stigma, in particular, can also impact help-seeking behaviors among young people. Approximately 1 in 10 young men and 1 in 8 young women have experienced problems with sexual function, but only a minority of these individuals report seeking help from a professional. This can be attributed partly to the perceived stigma and difficulties associated with self-disclosure (Mitchell et al., 2016).

\section{Decreased psychological wellbeing}

Decreased psychological wellbeing can increase engagement in sexual risk behavior. As indicated above, university students undergo significant change, may experience homesickness and face peer pressure, all of which can challenge psychological wellbeing in one way or another (Binfet \& Passmore, 2016). This can compound poor psychological wellbeing in relation to sexuality, specifically. In the US study of 2168 university students, Higgins, Mullinax, Trussell, Davidson, and Moore (2011) found that sexual guilt was negatively correlated with sexual satisfaction and that sexual selfcomfort and self-esteem were positively correlated with sexual satisfaction. Their study highlights the areas for enhancing sexual satisfaction among university students. Furthermore, a sizeable minority of young people experience sexual dysfunction, for which they do not seek support, which can adversely impact psychological wellbeing. It is noteworthy that depression, in particular, is related to sex with multiple partners, non-use of condoms, and decreased self-efficacy in relation to sexuality (Broccoli \& Sanchez, 2009; Jaspal, 2018). 


\section{Attitudes toward condoms}

Several studies suggest that attitudes toward condoms are associated with actual condom use (MacDonald \& Hynie, 2008). However, it is noteworthy that, in some studies, people with positive attitudes toward condoms may fail to use them - for other psychosocial reasons (Jaspal, 2018). Furthermore, expressing the intention to use condoms does not consistently translate into consistent condom use (MacDonald \& Hynie, 2008).

In their national study of Canadian university students, Milhausen et al. (2013) find that condom use is low among students - indeed, fewer than half of the students reported condom use in their last penetrative sexual encounter. In seeking to understand the rationale for deciding to use condoms, the most cited reason among students was birth control, rather than STI prevention. Moreover, in a study of students at eight universities in New Zealand, Connor, Psutka, Cousins, Gray, and Kypri (2013) found that just over half of all respondents reported using a condom in their last sexual encounter and that heavy drinking was a key determinant of sexual risk behavior. These studies suggest inconsistency of condom use among university students and the elevated risk of poor sexual health outcomes in this population.

\section{Alcohol misuse}

University students appear to be at especially high risk of alcohol misuse, which is a predictor of sexual risk behavior. It has been found that students drink significantly higher levels of alcohol than non-student peers (Kypri, Cronin, \& Wright, 2005), with one study highlighting that $64 \%$ of the UK students had engaged in binge drinking in the previous week (Cooke, Sniehotta, \& Schuz, 2007). Drinking behavior does appear to change during the course of one's time at university - one study revealed that alcohol consumption was highest in students' first year of university where the average age of a student is 19 years of age, compared to their final year where $70 \%$ stated that their drinking levels had dropped (Bewick et al., 2008). Crucially, alcohol misuse is associated with sexual risk-taking behavior among students, putting them at high risk of STIs, unwanted pregnancy, and sexual violence (Boyd, McCabe, \& Morales, 2005; Chanakira et al., 2014).

\section{The present study}

This study focuses on sexual health perceptions among a sample of firstyear students at a British university. The aim is to understand university students' perceptions of sexual risk, why they might engage in sexual risk behavior, the social and psychological circumstances surrounding sexual 
risk behavior, and their perceptions of sexual health screening. The data should contribute to informing effective programs for enhancing sexual health in this high-risk population.

\section{Method}

\section{Ethics}

The study received ethics approval from the Faculty of Health and Life Sciences Research Ethics Committee, De Montfort University Leicester, UK. Participants' real names have been replaced with pseudonyms and each quote includes their declared ethnicity.

\section{Context and participants}

Data were collected on a university campus in a medium-sized city in the East Midlands, United Kingdom. The university, which is located in the city center, has a student population of approximately 27,000. The student population is diverse - almost $70 \%$ of students are under the age of 21 ; almost $60 \%$ are female; just over $50 \%$ are from ethnic minority backgrounds; $20 \%$ have a declared disability and just over $13 \%$ are from neighborhoods with lower levels of participation in higher education.

Using a convenience sampling strategy, 16 first-year students were recruited to participate in a study of sexual behavior and sexual health. They participated voluntarily in exchange for course credits. Given the principal aim to obtain in-depth insight into participants' perceptions of sexual health, a sample size of 16 was deemed appropriate. Eligibility criteria for the study included: being heterosexual, sexually active, and a firstyear undergraduate student. Nine participants were female and 7 were male. Twelve participants were of White British ethnicity and 4 of British South Asian ethnicity. Participants were aged between 18 and 26 years $(\mathrm{M}=20.1, \mathrm{SD}=2.4)$.

\section{Procedure}

Participants read the study information sheet and signed a consent form. Interviews were guided by a semi-structured interview schedule consisting of a series of exploratory, open-ended questions. The schedule included questions/probes that elicited information concerning their sexual debut, current sexual behavior, their perceptions of sexual risk and sexual health, and sexual health screening behavior. Interviews were conducted by an undergraduate research assistant. Interviews lasted between 60 and 90 minutes, and were digitally recorded and transcribed verbatim. 


\section{Data analysis}

The data were analyzed using qualitative content analysis, which enables the analyst to identify, analyze and describe patterns emerging in qualitative data (Hsieh \& Shannon, 2005). It is a flexible qualitative technique that allows the analyst to identify key perceptions of, and meanings attributed to, sexual risk and sexual health among university students. This approach is used to shed light on attitudes and experiences in relation to sexual risk and sexual health. There was a focus on how interviewees conceptualized sexual risk, the meanings they attributed to sexual health, and how sexual health might fit within broader perceptions of identity and wellbeing.

The research assistant transcribed the recordings, and the author studied the transcripts and undertook the analysis. During each reading of the transcripts, preliminary interpretations were noted in the left margin. Then the right margin was used to collate these initial codes into overarching analytic observations, which captured the essential qualities of participants' accounts. These analytic observations are reported under the three subsections in the analysis section below. The interview extracts presented below are illustrative of the analytic observations.

\section{Analysis}

In this section, the following three content categories are described: (1) sexual freedom and exploration at university, (2) university environmental sexual risk factors, and (3) stigma as a barrier to sexual health.

\section{Sexual freedom and exploration at university}

Male interviewees noted a strong social norm in their male friendship circles that favored sexual exploration with women. Sex with multiple female partners was evaluated positively among male interviewees:

There's so many opportunities, more than what you would maybe get back at home. (Daniel, White British)

If you've spent 18 years in the same place you tend to just know the same people and then coming to uni, it's a whole new group of people. (Charles, White British)

Yeah, yeah, I don't know if this makes me sound like a predator innit but like at the start of the year like girls don't really like have any boyfriends or anything like that. They come to uni more free and it's easier to like sleep with 'cos during the year like they might be seeing someone or get boyfriends or whatever so it gets harder as times go on. (Bob, British South Asian)

Daniel and Charles highlighted the greater variety of potential sexual partners at university in comparison to their respective hometowns. Daniel 
noted the increased opportunities for sexual encounters at the university for this reason. Bob reported targeting freshers' week (the first week of the academic year) in order to obtain a higher number of sexual encounters with women. On the whole, male interviewees reported potential obstacles to acquiring sexual encounters with women, such as those listed by Bob, which they found frustrating because it interfered with their ability to engage in sexual exploration. Crucially, sex with multiple partners was deemed important because of social norms favoring such sexual behavior among young men at university, which they themselves described. There was a consensus among both male and female interviewees that the university experience, and freshers' week, in particular, was an opportunity to explore their sexualities:

Before uni I've been like really like blocked in, not being able to go out a lot so like being at uni kinda like excited me I thought "ohhhh [laughing] I get to mess about a bit”. (Anna, White British)

Anna and other interviewees discussed the intensity of their college studies (prior to enrolling at university) which had led them to focus on their studies with little opportunity for sexual exploration. They generally felt that the sense of sexual deprivation at college increased the desire to explore their sexualities while at university. For Anna, such sexual exploration consisted of casual sexual encounters with multiple male partners. Virtually all of the interviewees contrasted their experience of sexual exploration at university with their struggle to express their sexualities while living with their parents prior to enrolling at university:

I think there's a lot more opportunities, like you meet a lot more people, have sex and then they like they can find someone and can keep having sex with them [laughing]. Like I don't suppose you do that a lot say in sixth form or something because you're still at home as well. (Danielle, White British)

I think going uni is, yeah, like a big changer ... There's a lot more nightlife, do you know what I mean? There's a lot more that goes on like especially like its like you're free from, like from what your parents, like you've got your own place, like you're free, and you can like do whatever you want in that place and also like you might not be able to go back on nights out and stuff, so it's a lot more relaxed. You can do more of what you want. (Daniel, White British)

Like Daniel and Danielle, several interviewees reflected on their experience of living at home and the difficulties that this posed for sexual exploration. Nightlife at university was consensually construed as facilitating access to potential sexual partners. Daniel and others constructed nightclubs as sexualized environments in which sexual exploration was possible and encouraged. Moreover, interviewees noted that it was possible to return home at any hour - or not at all - while living alone at university. 
Indeed, Daniel described university as a form of freedom, principally from the constraints imposed by his parents, and noted that at university he possessed a physical space in which he could actually have sexual encounters. There was a perceived regulation of sexuality in the home environment, which interviewees perceived to disrupt their ability to explore their sexual identities. There was a pervasive belief that it was impossible to "do whatever you want" at home but that at university there was greater freedom:

Obviously at uni it's a lot easier to like have one night stands 'cos your parents aren't home and to just meet new people and just have fun and that. (Caleb, White British)

I think again just like having the chance. You're away from your parents so you've got like you can do more than obviously can't when you're at home. You can't come home late and you've got to give an explanation and stuff so I think that uni you just go back to your flat. (Bindu, British South Asian)

Both male and female interviewees referred to parental regulation of sexuality while living at home. Caleb and Bindu noted that they felt unable to have as many casual sexual encounters while living at home because they were cohabiting with their parents. Bindu, a British South Asian woman, indicated parental pressure to return home at an early hour and to provide "explanations" for arriving home late. In some ethnic minority cultural groups, there is significant pressure to conform to cultural norms concerning sexual abstinence before marriage (Uddin, 2006). Such parental regulation of sexual behavior was perceived as an obstacle to sexual exploration, which, conversely, was deemed possible at university. Most importantly, having one's own space was a facilitator of sexual activity, according to interviewees. In view of parental regulation of behavior while living at home, most interviewees reported the sense of liberation that they experienced upon moving away from home and enrolling at university:

I think because at home I've been restricted too much I kinda like acted rebellious on things and now I have that freedom it's like "oh maybe it's time for me to like act upon it because I'm independent". (Anna, White British)

Anna described her sexual behavior at university as an act of rebellion in the face of perceived restrictions at home, that is, parental regulation of her sexual behavior. She celebrated her newfound freedom and independence by "acting upon it" and engaging in behaviors which she did not deem possible when cohabiting with her parents. The correlation between parental regulation at home and engaging in sex with multiple partners was observable in several participants' accounts, which suggested that individuals' sexual behavior may constitute a response to the lack of freedom and independence which they associate with pre-university life at home. Yet, sex with multiple partners may pose risks to sexual health. Some of the risk factors specific to the university environment are discussed next. 


\section{University environmental sexual risk factors}

All of the interviewees had an understanding of the notion of "sexual risk" and most described this as synonymous with "unprotected sex". The vast majority of interviewees regarded unwanted pregnancy as the main hazard and relatively few participants were cognizant of the risk of STIs. Even when they did acknowledge the risk of STIs, less importance was appended to this than to unwanted pregnancy. Furthermore, individuals' risk perceptions appeared to be based on subjective factors, which suggested a lack of sexual health knowledge. For instance, Frank described a problematic strategy for protecting his sexual health:

Obviously you know each other. You know that you're both clean so it's not risky...

Everyone who is new I use protection with and when it's someone I've been with a few times who I know are clean then if it's agreed then I don't really need to.

(Frank, White British)

Frank's belief that "knowing" a sexual partner reduced the risk of STIs was widespread in the participant sample. He used the term "clean" to describe the absence of STIs, thereby reinforcing the stigma associated with STIs, which is discussed in the next subsection. His view was that "knowing" a sexual partner was a protective factor, which highlighted both a lack of STI knowledge and an elevated risk of infection. It is clear that this strategy to prevent STIs is unlikely to be effective in the long term.

Like Frank, all of the participants reflected on their own experiences of sexual risk at university and most acknowledged that their behavior had been, or continued to be, "risky". Being in the university environment was described as being conducive to sexual risk behavior:

I think freshers' week is when everyone just goes crazy but then but then you just forget about it and you start realising "oh crap I need to stop" ... thinking straight. (Anna, White British)

My friends were literally like "ahhhhh ahhhhh you haven't got on there yet" so the pressure was massive. You just wanted to get on there literally just find someone... The idea of ... [I] think it's just vanity like "oh my god I need to go out I need to have a good time I need to show I'm good or whatever I'm attractive" and it's like I think it sometimes clouds anything real really. (Andy, White British)

Anna noted that freshers' week, in particular, was widely understood to be a time for sexual experimentation and exploration, which she described as a period when "everyone goes crazy". This was essentially a metaphor for risk behavior. The important point is that freshers' week itself was deemed to be the causal factor in sexual risk behavior. Similarly, Andy noted the peer pressure to engage in sex with multiple partners, which compelled him to identify sexual partners hastily in order to meet the expectations of his peers. This issue was closely associated with self-esteem 
and a positive self-conception. Indeed, several interviewees noted that, by engaging in sex with multiple partners (and, thus, meeting the expectations of their peers), they were able to demonstrate their worth as individuals. In Andy's case, this entailed demonstrating that he was physically attractive to women at university. The drive for positive self-presentation and selfesteem was widely acknowledged by participants, who generally noted that this could override rational thinking and, thus, lead to engagement in sexual risk behavior.

In addition to sex with multiple partners, engagement in condomless sex was reported by almost all of the interviewees. Although the majority recognized and understood the benefits of condom use - for preventing both STIs and unwanted pregnancy - they acknowledged that they had had "slip-ups" in the past. In reflecting on the reasons for these occasional occurrences, they reported prioritizing the quality of the sexual encounter over sexual health:

A lot of times if you're just gonna go and have sex and you don't have a condom or something you're just gonna do it anyway and there's a lot of opportunity like there's so many people at uni. (Danielle, White British)

I try and use protection... Kinda using contraception tends to be a mood killer especially if people are drinking... When you're drunk it's just one track mind not wanting to ruin the flow of things. I think just physically it's a bit more organic and it just feels better. (Charles, White British)

Like all interviewees, Danielle and Charles were aware of the effectiveness of condom use in protecting sexual health and of the norm that condoms should be used for casual sexual encounters. However, despite this knowledge, there was an acknowledgment that condoms were not used consistently. Danielle noted the practical point that condoms were not always available just before a sexual encounter and that, in her experience, this resulted in a sexual risk event. Danielle appeared to be suggesting that this was both inevitable and widespread among her peers.

Furthermore, Charles reported attempting to use condoms consistently due to the norm concerning its role in good sexual health. However, he highlighted some of the shortcomings associated with condom use. First, he described condom use as a "mood killer" which might obscure the focus on sensation and sensuality and essentially constitute a distraction from the sex act itself, thereby "ruining the flow of things". Second, he highlighted both the physical and psychological benefits of condomless sex in that "it just feels better". He referred both to the removal of a physical barrier, which might enhance physical sensation, but also to the notion that condomless sex is "more organic", thereby promoting a more authentic and intimate sexual encounter. In short, these perceived benefits could 
sometimes outweigh the risks of condomless sex and indeed the benefits of condom use for sexual health.

In his account, Charles indicated that alcohol misuse could aggravate the negative psychosocial impact of condom use, increasing the likelihood of condomless sex. Consistent with existing research in this area (Bewick et al., 2008; Chanakira et al., 2014), several interviewees acknowledged the role of alcohol in reducing inhibitions and in increasing the likelihood of a sexual risk event:

I just got absolutely hammered and I just don't remember nothing and that's it just so easy to get to that point. (Andy, White British)

Alcohol is like a liquid confidence so yeah you know you if you're feeling a bit anxious you drink you get confident, you wanna join in the partying, you do stuff. (Georgia, White British)

Students may be in a position where not only rational decision-making but also memory is compromised as a result of alcohol consumption prior to a sexual encounter. Andy reported not remembering what he had done when under the influence of alcohol, which in turn undermined his ability to take steps to prevent his risk of an STI following the risk event. Like Georgia, several interviewees acknowledged that they used, and perhaps misused, alcohol in order to gain the confidence to engage in the behaviors expected of them at university. For instance, some interviewees reported feeling nervous about attending parties where they might meet potential sexual partners and consumed alcohol to do so more effectively. Thus, for many of the respondents, the causal factor in alcohol misuse was psychosocial in origin. Many in turn reported a sexual risk event after consuming alcohol.

Charles alluded to the psychosocial underpinnings of sexual risk behavior. Similarly, a number of interviewees described a potential relationship between their psychosocial state and their risk behavior:

I think it's [condomless sex] an expression of love so like I've had unprotected sex because of trusting the person... It's good to like kinda like experiment with different kinds of sex. (Anna, White British)

After my ex, in order for me to move on from him, I just went crazy, done numerous guys. I even once done 2 guys in the same day which is just so bad [laughing] I don't know how just at the time I just did it I didn't even care. I just wanted to move on and yeah now I think about it I know for a fact it's really messed up. (Jane, White British)

In her account, Anna noted that condomless sex could constitute an expression of intimacy possibly because of the removal of a physical barrier and the interpersonal trust that is implicit in the non-use of condoms. In her reflections on her sexual behavior at university, Jane described the 
psychological distress that she experienced following the breakdown of her relationship with her former boyfriend. In order to alleviate this distress, Jane reported having multiple casual sexual encounters, which constituted her way of "moving on". Her account also revealed decreased self-esteem and her consequential lack of self-care - she was alluding to her indifference to the potential consequences of her sexual risk behavior. However, in hindsight, she perceived her sexual behavior to have been irrational and excessively risky, and expressed dismay in relation to it: "it's really messed up". Indeed, existing research has established a relationship between psychological adversity and sexual risk-taking (Jaspal, 2018), which highlights the need for effective interventions to reduce the impact of distress and to promote more sustainable, adaptive coping strategies.

\section{Stigma as a barrier to sexual health}

In the previous section, there was some evidence of stigma in relation to sex with multiple casual partners and to condomless sex. It must be noted that female interviewees perceived stigma in relation to sex with multiple partners and that this conversely was positively valued among male interviewees. The young women who participated in this study referred to such sexual behavior as "going crazy" and "really messed up", and clearly aspired to change this behavior in the future. The stigma that individuals themselves appended to their previous behavior was observable in their accounts:

\footnotetext{
For me, it's not me. I knew it wasn't me. I'm not the person to be having sex every single day and all that stuff. I'm not that person. I've realized I'm not that sorta... University shows your true colours for a certain period of time. You've got to realize that's not you and it's not right at all. (Charlotte, White British)
}

I have looked back and I was like "Why did I do this?" "Why was I like this?" and people would assume "oh she's this, she's that" when really there a valid reason behind it. (Jane, White British)

In reflecting on her sexual behavior during the first few months of university, Charlotte drew a clear distinction between her "true" identity and the inauthentic identity that she believed to have emerged as a result of being at university. Crucially, the inauthentic identity was one of sexual promiscuity - she rejected this identity as "not me". She appeared to reject this identity because of the social stigma appended to it. This was clearly indicated by her observation that "it's not right at all", which was a reference to negative societal views about sex with multiple partners. Similarly, Jane expressed concern about potential stigma from other people if they were to learn of her sexual behavior - she believed that she would be judged and denigrated by others. Moreover, there was an element of 
internalized stigma given her own disapproval of her previous behavior. Indeed, she questioned the reasons underpinning her behavior and expressed confusion. Anna anticipated judgment from others due to her sexual risk behavior:

They [her peers] do judge me a lot. They do talk to me about it but I feel it's not their business to ask... They say "you need to calm down a bit" but it's literally the same guys. It's not like I'm bringing [home] different people. (Anna, White British)

On the basis of these data, it is easy to see why young women may refrain from disclosing their sexual experiences to significant others, such as friends and family members, which in turn decreases access to potential sources of social support. This is problematic as social support is an effective strategy for coping with psychological adversity (Jaspal, 2018). Interviewees also expressed trepidation about engaging with sexual health services due to anticipated stigma:

I think people are a bit scared to do so... I've tried to go to a sex clinic to get free condoms but was a bit scared like I always want someone to come with me... I don't know, it's embarrassing. It's embarrassing like people might be judging you or the nurses might look at you and like "ah is she the type that does this sort of thing?” ... I actually haven't. I've just gone there then walked out. (Anna, British)

Often if you go in, it's embarrassing. You have to talk to a receptionist and you're worried other people can hear you. (Emily, White British)

Participants expressed fear of going to a sexual health clinic for advice and to obtain free condoms due to embarrassment. Anna anticipated stigma from healthcare professionals who she thought might be judgmental toward her and categorize her as the prototypical sexual "risk-taker". On the other hand, Emily was concerned about being overheard in the sexual health clinic which might also engender stigma from others. Anticipated stigma led some individuals to disengage from the sexual health clinic after arriving there or not to engage at all. Participants like Izzy appeared to have internalized the stigma that they anticipated from others, and suggested that a sexual health clinic is "not my environment":

I remember when I had to do that once I felt quite uncomfortable personally going to a clinic. It's not my environment but I didn't know where I could find one I had to google it and things like that before I could find somewhere to go. (Izzy, White British)

Izzy appeared to be suggesting that she did not view herself as the sort of person who might require sexual health services, despite acknowledging that she had engaged in risk behaviors. Interviewees perceived and accepted a negative stereotype of people who attend sexual health services. This perception suggests that stigma does surround attendance at sexual health clinics and that individuals attempt to deflect the stigma by disengaging from 
services. It is noteworthy that, in some cases, interviewees reported negative experiences of sexual health services, which led to skepticism about using them:

I don't think I am [happy to visit a sexual health clinic] anymore because I specifically asked for no letters to be sent to my house and I got home from uni a couple like I think last month and there was a letter on my bed from them that had said I'd been discharged from them and I was like "well it's a letter and its been opened" so obviously my parents had seen it. (Hayley, White British)

Some individuals reported difficulties in discussing sexual health issues with their parents due to the associated stigma and wished to delineate their sexual identities from their family identities. Hayley's account illustrated a breach in confidentiality, which increased her fear of attending a sexual health clinic while at university. Interviewees did not wish to be seen to be using sexual health services and, importantly, they did not want their parents to be aware of their sexual behavior or use of sexual health services. An adverse clinical experience of this kind can undermine confidence in clinical services and potentially lead to decreased help-seeking behavior.

Several of the interviewees reported no knowledge of sexual health services in their city of study or how to access them. This could potentially be attributed to the decreased discussion of sexual health issues at university and to the active avoidance of these issues on the part of students themselves as a result of the associated stigma:

I've noticed more advertising for being tested for chlamydia and that kinda thing but STDs as a general thing I don't think schools or educational institutes talk about it enough because people still put themselves into situations and I don't know. No, it's not talked about it enough. (Georgia, White British)

Georgia's account suggested a need for increased awareness-raising and signposting to sexual health services among university students. Social stigma appears to be a significant obstacle to open and transparent discussion regarding this important topic.

\section{Discussion}

There is a range of social, psychological and environmental factors that shape sexual behavior among first-year university students in the UK. This study suggests that these factors include the increased sexual freedom that students generally perceive upon arriving at university and living independently away from home; social norms and practices in relation to sexuality in their peer networks at university; and social stigma associated with sexual exploration and sexual health screening among women. These factors are likely to be especially relevant to first-year university students, in 
particular, given that they have recently enrolled at university and are at an early stage of transition from life at home to independent living at university (Curtis, 2015). The results are broadly consistent with existing research and, thus, suggest that these social, psychological and environmental factors should be acknowledged in future sexual health education programs designed for university students.

\section{Social psychological underpinnings of sexual risk}

There was a clear social psychological basis to sexual risk among the university students who participated in this study. Interviewees unanimously noted the sexual freedom associated with living independently at university and the multifarious opportunities for sexual exploration in this environment. They contrasted this sense of freedom with parental regulation of their sexual behavior and the restrictions that they faced while living at home. Individuals may experience an element of sexual frustration at home due to the perceived lack of sexual freedom or opportunity, leading them to embark upon a journey of sexual exploration at university - often with multiple partners and without the use of condoms. All of the interviewees were, or had been, in this situation and, thus, collectively viewed sexual exploration as a priority while at university. It is easy to see how this can become a social norm at university, which, for male interviewees at least, is positively evaluated and celebrated. Sexual exploration may be a defensive response to perceived parental regulation. Yet, many interviewees embarked upon their journey of sexual exploration with limited sexual health knowledge possibly because this had been difficult to access while living at home. Furthermore, their risk behavior was reportedly facilitated and accentuated by alcohol misuse, which has been observed in previous research (Chanakira et al., 2014).

Despite their limited sexual health knowledge, interviewees were cognizant of the notion of sexual risk. However, most of them described sexual risk in terms of unwanted pregnancy and there was only cursory acknowledgment of STIs as a potential hazard to sexual health. In the interviews, chlamydia and gonorrhea were repeatedly trivialized and participants often discussed STIs humorously, such as by laughing when talking about STIs. This suggested that STIs were not considered a serious concern. Moreover, many respondents had not used sexual health services while at university and reported being unaware of how to access them. They generally refrained from doing so, despite engaging in behaviors that clearly put their sexual health at risk. The data reveal a need to expand students' knowledge surrounding sexual health, STIs and ways of accessing sexual health services. In considering the relevance of these findings, it is important to 
acknowledge the high incidence of bacterial STIs among young people, which is especially concerning in the context of growing antibiotic resistance (Lepkowska, 2018).

Given the social stigma that surrounds sexual exploration among women, female interviewees reported feeling unable to discuss their sexuality openly and some described judgmental and denigrating reactions from peers when they did disclose sexual risk behavior. Some women in the study experienced guilt and other negative emotions in reflecting on their sexual behavior, which precluded open discussion and help-seeking. In view of the social stigma associated with sexual exploration, many of the female interviewees refrained from accessing sexual health services - they anticipated stigma both from healthcare professionals and from peers. More generally, both male and female interviewees believed that there was only a limited discussion of sexual health on campus. In view of the high STI incidence in young people, it is essential that sexual health services be more visible and accessible to first-year university students - a significant population in sexual health promotion.

\section{Toward a university sexual health education program}

Existing research that highlights the role of inaccurate risk perception, social norms, decreased psychological wellbeing and alcohol misuse in sexual risk behavior among university students. When viewed in the context of this existing research, the results of this small-scale qualitative study provide important insights into the potential design of university sexual health education programs.

University students would benefit from the skills, competence, and resources to make informed decisions about their sexual behavior and to protect their sexual health - through both prevention and treatment (Pound et al., 2017). It would be beneficial for students to be exposed to a compulsory sexual health education program, which ultimately empowers them to access knowledge, to build competence, and to access sexual health services. It would, of course, be preferable for this program to commence prior to enrollment in university in order to prepare students effectively prior to this life stage which is associated with increased sexual activity. However, given the STI burden faced by young people who are over-represented among first-year students (Department for Education, 2007), it is essential that this commences upon enrollment in university - a university sexual health education program would be of universal benefit in the United Kingdom. In the remainder of this article, four broad principles are described for enhancing such a program. 
First, condom distribution must continue to be a central focus of sexual health education programs. Students generally acknowledged the importance of condom use for maintaining good sexual health and many aspire to use them consistently. Yet, many of the respondents who reported a sexual risk event had not had access to a condom and, thus, proceeded without one. It is also noteworthy that some actively choose not to use condoms given the widespread perception that condomless sex gives a greater meaning and intimacy to a sexual encounter (Corbett, DicksonGomez, Hilario, \& Weeks, 2009). On the one hand, sexual health education programs must increase access to condoms, principally by making them available to students free of charge and in a variety of venues. For instance, vending machines could be installed in key locations on campus, which would increase access to condoms at all times. On the other hand, sexual health education programs must represent condom use as sexually pleasurable and challenge the notion that condom use decreases physical sensation, interpersonal connection, and emotional intimacy. This view was pervasive among interviewees and could undermine condom acceptability among university students.

Second, psychological wellbeing in relation to sexuality must be acknowledged. The World Health Organisation (2006, p. 5) describes sexual health aptly as "a state of physical, emotional, mental and social well-being in relation to sexuality." Yet, students' definitions of sexual health and sexual risk focused largely on the avoidance of unwanted pregnancy and, to a lesser extent, the absence of STIs. The psychosocial component of sexual health was simply not acknowledged by interviewees. However, it is evident from the results that interviewees reported psychological distress in relation to relationship dissolution, peer pressure to engage in particular sexual behaviors, the misuse of alcohol in order to restore confidence and selfesteem, and poor mental health. These psychosocial factors can influence the sexual behaviors of students. Sexual health education programs should endeavor to sensitize students to the importance of psychological wellbeing in relation to sexuality and to channel those facing difficulties toward coping strategies that are more effective and that do not compromise sexual health outcomes in the long term.

Third, sexual health needs to be positioned within the broader context of student identity, development, and well being. First-year students undergo significant change when they begin university and many experience what they perceive to be sexual freedom for the first time. An effective sexual health education program would empower university students to engage in sexual exploration safely - both for their psychological and physical health. Important topics of discussion would include sexual diversity, sexual consent, methods for preventing STIs, and the relationship between alcohol 
use and sexual health. Students should be able to discuss their sexualities in an affirmative and accepting environment, as this might reduce both stigma and shame in relation to sexuality and preclude concealment while promoting disclosure and help-seeking. Furthermore, it must be acknowledged that students have multiple identity elements - a principal identity element among students is that of being a student but it is not the only one. For instance, some of the students who participated in this study were of British South Asian origin and described the cultural and religious norms that sometimes accentuated the desire for sexual freedom and exploration at university. As universities become increasingly diverse, there is a need for them to be cognizant of growing diversity in both pedagogy and pastoral support (Jaspal, 2015). A culturally competent approach to sexual health education is necessary given that this will increase the likelihood of engagement with, and acceptability of, a sexual health education program among students from diverse backgrounds (Fish, Papaloukas, Jaspal, \& Williamson, 2016).

Fourth, participants in this study exhibited a surprising lack of awareness of how to access sexual health services while at university. There is also existing research that describes the many barriers to help-seeking behavior among students (e.g. Mitchell et al., 2016). There must be a clear pathway between any sexual health education program and local sexual health services, ensuring that all students who undertake the program are immediately made aware of the availability of services and, crucially, how to access them. Moreover, sexual health services need to be made more available to students - especially outside of clinical environments. For instance, Jaspal (2018) found that gay men at risk of HIV were more likely to test for HIV regularly if they were able to access testing in a variety of contexts, such as in community settings and at home using a self-testing kit. Similarly, sexual health services (including both social psychological and medical support) should be made available on university campuses, which would enable students to access services more easily - especially for those who fear social stigma.

\section{Conclusions}

First-year university students are an under-explored population in sexual health research in the United Kingdom despite being at high risk of poor sexual health. This study demonstrates the relevance of psychosocial issues to their sexual health. First-year students may seek to exploit their newfound sexual freedom upon living independently away from home for the first time. Coercive social norms in relation to sexuality in their peer networks at university may be difficult to resist and lead to increased sexual 
risk-taking. Yet, the social stigma associated with sexual exploration and sexual health screening - especially among women - may preclude self-disclosure, the derivation of social support and engagement with sexual health services. Given the significant STI burden faced by young people, every university in the United Kingdom should develop, and promote engagement with, an effective sexual health education program that is cognizant of the social psychological underpinnings of sexual health.

\section{References}

Bewick, B. M., Mulhern, B., Barkham, M., Trusler, K., Hill, A. J., \& Stiles, W. B. (2008). Changes in undergraduate student alcohol consumption as they progress through university. BMC Public Health, 8(1), 163. doi:10.1186/1471-2458-8-163

Binfet, J., \& Passmore, H. (2016). Hounds and homesickness: The effects of an animalassisted therapeutic intervention for first-year university students. Anthrozoös, 29, 441-454. doi:10.1080/08927936.2016.1181364

Boyd, C., McCabe, S. E., \& Morales, M. (2005). College students' alcohol use: A critical review. Annual Review of Nursing Research, 23(1), 179-211. doi:10.1891/0739-6686.23.1. 179

Broccoli, T. L., \& Sanchez, D. T. (2009). Implicit hopelessness and condom use frequency: Exploring nonconscious predictors of sexual risk behavior. Journal of Applied Social Psychology, 39, 430-448.

Chanakira, E., O’Cathain, A., Goyder, E. C., \& Freeman, J. V. (2014). Factors perceived to influence risky sexual behaviours among university students in the United Kingdom: A qualitative telephone interview study. BMC Public Health, 14(1), 1055. doi:10.1186/14712458-14-1055

Collado, A., Johnson, P. S., Loya, J. M., Johnson, M. W., \& Yi, R. (2017). Discounting of condom-protected sex as a measure of high risk for sexually transmitted infection among college students. Archives of Sexual Behavior, 46, 2187-2195. doi:10.1007/s10508-0160836-x

Connor, J., Psutka, R., Cousins, K., Gray, A., \& Kypri, K. (2013). Risky drinking, risky sex: A national study of New Zealand university students. Alcoholism: Clinical and Experimental Research, 37, 1971-1978. doi:10.1111/acer.12175

Cooke, R., Sniehotta, F., \& Schuz, B. (2007). Predicting binge-drinking behaviour using an extended TPB: Examining the impact of anticipated regret and descriptive norms. Alcohol and Alcoholism, 42, 84-91. doi:10.1093/alcalc/agl115

Corbett, A. M., Dickson-Gomez, J., Hilario, H., \& Weeks, M. R. (2009). A little thing called love: Condom use among high-risk primary heterosexual couples. Perspectives on Sexual and Reproductive Health, 41, 218-224. doi:10.1363/4121809

Curtis, M. L. (2015). Student identities in new spaces of higher education (Unpublished $\mathrm{PhD}$ dissertation). University of Brighton, Brighton, UK. https://cris.brighton.ac.uk/ws/portalfiles/portal/4753301/Mandy+Curtis+-+Final+Phd.pdf.

Department of Education. (2017). Participation rates in higher education: Academic years 2006/2007 - 2015/2016 (Provisional). https://assets.publishing.service.gov.uk/government/ uploads/system/uploads/attachment_data/file/648165/HEIPR_PUBLICATION_2015-16. pdf. (Accessed 22 September 2019). 
Fish, J., Papaloukas, P., Jaspal, R., \& Williamson, I. (2016). Equality in sexual health promotion: A systematic review of effective interventions for black and minority ethnic men who have sex with men. BMC Public Health, 16(1), 810. doi:10.1186/s12889-016-3418-x

Foster, L. R., \& Byers, E. S. (2008). Predictors of stigma and shame related to sexually transmitted infections: Attitudes, education, and knowledge. Canadian Journal of Human Sexuality, 17, 193-202.

Gardner, M., \& Steinberg, L. (2005). Peer influence on risk taking, risk preference, and risky decision making in adolescence and adulthood: An experimental study. Developmental Psychology, 41, 625-635. doi:10.1037/0012-1649.41.4.625

Goundry, A. L., Finlay, E. R., \& Llewellyn, C. D. (2013). Talking about links between sexually transmitted infections and infertility with college and university students from SE England, UK: A qualitative study. Reproductive Health, 10(1), 47. doi:10.1186/1742-4755$10-47$

Hayter, M., \& Harrison, C. (2008). Gendered attitudes towards sexual relationships among adolescents attending nurse led sexual health clinics in England: A qualitative study. Journal of Clinical Nursing, 17, 2963-2971. doi:10.1111/j.1365-2702.2008.02515.x

Higgins, J. A., Mullinax, M., Trussell, J., Davidson, J. K., \& Moore, N. B. (2011). Sexual satisfaction and sexual health among university students in the United States. American Journal of Public Health, 101, 1643-1654. doi:10.2105/AJPH.2011.300154

Hsieh, H. F., \& Shannon, S. E. (2005). Three approaches to qualitative content analysis. Qualitative Health Research, 15, 1277-1288. doi:10.1177/1049732305276687

Jaspal, R. (2015). Constructing and protecting identity in a diverse higher education context. Perspectives: Policy and Practice in Higher Education, 19, 27-134. doi:10.1080/ 13603108.2015.1071291

Jaspal, R. (2018). Enhancing sexual health, self-identity and wellbeing among men who have sex with men: A guide for practitioners. London: Jessica Kingsley Publishers.

Kypri, K., Cronin, M., \& Wright, C. S. (2005). Do University students drink more hazardously than their non-student peers? Addiction, 100, 713-714. doi:10.1111/j.1360-0443. 2005.01116.x

Lepkowska, D. (2018). The implications of rising antibiotic resistance in STIs. British Journal of School Nursing, 13, 114. doi:10.12968/bjsn.2018.13.3.114

Lorimer, K., Reid, M. E., \& Hart, G. J. (2009). It has to speak to people's everyday life": qualitative study of men and women's willingness to participate in a non-medical approach to Chlamydia trachomatis screening. Sexually Transmitted Infections, 85, 201-205. doi:10.1136/sti.2008.031138

MacDonald, T. K., \& Hynie, M. (2008). Ambivalence and unprotected sex: Failure to predict sexual activity and decreased condom use. Journal of Applied Social Psychology, 38, 1092-1107. doi:10.1111/j.1559-1816.2008.00340.x

Milhausen, R. R., McKay, A., Graham, C. A., Crosby, R. A., Yarber, W. L., \& Sanders, S. A. (2013). Prevalence and predictors of condom use in a national sample of Canadian university students. The Canadian Journal of Human Sexuality, 22, 142-151. doi:10.3138/ cjhs. 2316

Mitchell, K. R., Geary, R., Graham, C., Clifton, S., Mercer, C. H., Lewis, R., ... Wellings, K. (2016). Sexual function in 16- to 21-year-olds in Britain. Journal of Adolescent Health, 59, 422-428. doi:10.1016/j.jadohealth.2016.05.017

Patton, L. D., Renn, K. A., Guido, F. M., \& Quaye, S. J. (2016). Student development in college: Theory, research and practice. San Francisco, CA: Jossey-Bass.

Pitts, M., \& Rahman, Q. (2001). Which Behaviors Constitute "Having Sex" Among University Students in the UK?. Archives of Sexual Behavior, 30(2), 169-176. 
Pound, P., Denford, S., Shucksmith, J., Tanton, C., Johnson, A. M., Owen, J., ... Campbell, R. (2017). What is best practice in sex and relationship education? A synthesis of evidence, including stakeholders' views. BMJ Open, 7, e014791. doi:10.1136/bmjopen-2016014791

Public Health England. (2015). Sexually transmitted infections in England print. Retrieved from https://www.gov.uk/government/uploads/system/uploads/attachment_data/file/ 536208/STI_poster.pdf. (Accessed 21 April 2019).

Public Health England. (2018a). An STI is diagnosed in a young person every 4 minutes in England. Retrieved from https://www.gov.uk/government/news/an-sti-is-diagnosed-in-ayoung-person-every-4-minutes-in-england (Accessed 21 April 2019).

Public Health England. (2018b). United Kingdom national HIV surveillance data tables. https://assets.publishing.service.gov.uk/government/uploads/system/uploads/attachment_ data/file/768932/National_Tables_2018_v1.2.xls (Accessed 21 April 2019).

Public Health England. (2019). Sexually transmitted infections and screening for Chlamydia in England, 2018. https://assets.publishing.service.gov.uk/government/uploads/system/ uploads/attachment_data/file/806118/hpr1919_stis-ncsp_ann18.pdf (Accessed 23 April 2019).

Uddin, M. S. (2006). Arranged marriage: A dilemma for young British Asians. Diversity in Health and Social Care, 3, 211-219.

Vivancos, R., Abubakar, I., \& Hunter, P.R. (2008). Sex, drugs and sexually transmitted infections in British university students. International Journal of STD and Aids, 19, 370-377. doi:10.1258/ijsa.2007.007176

World Health Organisation. (2006). Defining sexual health. Report of a technical consultation on sexual health, 28-31 January 2002. Geneva: WHO Press. www.who.int/reproductivehealth/publications/sexual_health/defining_sexual_health.pdf (Accessed 17 May 2019). 